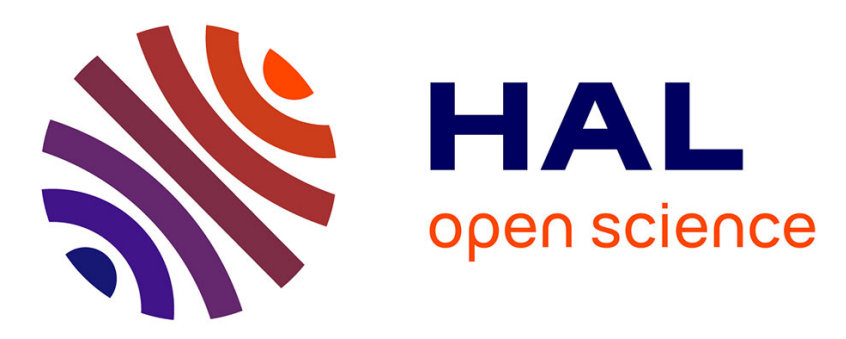

\title{
French field results (1985-2005) on factors affecting fertility of frozen stallion semen
}

\author{
Marianne Vidament
}

\section{To cite this version:}

Marianne Vidament. French field results (1985-2005) on factors affecting fertility of frozen stallion semen. 4. International Symposium on Stallion Reproduction, International Society of Equine Reproduction (ISER). INT., Feb 2005, Hannover, Germany. hal-02762081

\section{HAL Id: hal-02762081 \\ https://hal.inrae.fr/hal-02762081}

Submitted on 4 Jun 2020

HAL is a multi-disciplinary open access archive for the deposit and dissemination of scientific research documents, whether they are published or not. The documents may come from teaching and research institutions in France or abroad, or from public or private research centers.
L'archive ouverte pluridisciplinaire HAL, est destinée au dépôt et à la diffusion de documents scientifiques de niveau recherche, publiés ou non, émanant des établissements d'enseignement et de recherche français ou étrangers, des laboratoires publics ou privés. 


\title{
French field results (1985-2005) on factors affecting fertility of frozen stallion semen
}

\author{
M. VIDAMENT \\ UMR Physiologie de la Reproduction et des Comportements \\ INRA-CNRS-Université Tours-Haras Nationaux, 37380 Nouzilly, France \\ Corresponding author: M. Vidament \\ tel: 33247427805 \\ fax: 33247427743 \\ vidament@tours.inra.fr \\ Correspondence address: \\ PRC, INRA, 37380 Nouzilly, France \\ vidament@tours.inra.fr
}

\begin{abstract}
Results on procedures for freezing stallion semen and the subsequent fertility during 20 years are presented. The present system applied in French National Stud includes 1) a freezing protocol (dilution in milk, centrifugation and addition of freezing extender (INRA82 + egg yolk $(2 \%, \mathrm{v} / \mathrm{v})+$ glycerol $(2.5 \%, \mathrm{v} / \mathrm{v})$ at $22^{\circ} \mathrm{C}$, a moderate cooling rate to $4^{\circ} \mathrm{C}$ and freezing at $-60^{\circ} \mathrm{C} / \mathrm{min}$ in $0.5-\mathrm{ml}$ straws); 2) selection of ejaculates showing post-thaw rapid motility $>35 \%$; and 3) an insemination protocol (mares examined once daily, 2 AI of $400 \times 10^{6}$ spermatozoa $24 \mathrm{~h}$ apart before ovulation, sufficient number of straws to have the possibility to perform 6 AI of 400 x $10^{6}$ total spermatozoa, i.e. $2.4 \times 10^{9}$ total spermatozoa available per mare per season). This system was applied to $>110$ stallions per year, the average post-thaw motility of ejaculates was $50 \%$ (>1800 ejaculates) before selection. The semen freezability was defined as the number of selected ejaculates divided by the total number of ejaculates frozen. Of the stallions, 5, 4, 5, 21 and 64\% had semen freezability of 0 to 10, 10 to 33, 33 to 60, 60 to 90 and over $90 \%$, respectively. Per-cycle pregnancy rate was 45 to $48 \%$ (>1500 mares per year, 1.8 cycles per mare) and foaling rate $64 \%$. In comparison, per-cycle pregnancy rate and foaling rate of mares hand-mated to stallions were 57 to $59 \%$ and $64 \%$, respectively. The average number of straws used was 32 to 35 (1.75 x $10^{9}$ total spermatozoa) per mare per season. According to our results and the literature, the most important factors for improving fertility of frozen equine semen include: 1) a low concentration of glycerol (2 to 3.5\% final concentration); 2) a suitable base extender for freezing like Lactose-glucose EDTA or INRA82; 3) a post-thaw motility $>30$ to $35 \%$; and 4) a sufficient number of spermatozoa per mare per season (1.5 to $2 \times 10^{9}$ total spermatozoa for 2 to 3 cycles) divided into small units. Numbers of spermatozoa, lower than $750.10^{6}$ total spermatozoa per cycle, could result in lower per-cycle pregnancy rate with higher additional costs for management of mares. Because there are no particular regulations on quality and quantity of equine semen in the European Community, there is a need for the uniformity of information about frozen semen. A codification is suggested, based on the number of spermatozoa available per mare per season, the post-thaw motility and the final glycerol concentration.
\end{abstract}

Keywords: Horse; Equine; Spermatozoa; Cryopreservation; Fertility; Freezability; Glycerol 


\section{Introduction}

In France, the use of frozen semen is prominent in warm-blood horse breeds. In 2004, 6900 mares were inseminated with frozen semen (2200 with National Stud stallions and 4700 with private stallions), compared to 2150 mares in 1997 and only 90 mares in 1985 . Within the main French breed of sport horses, Selle Français, 35\% of the 7500 mares booked to private stallions are inseminated with frozen semen. Semen is mainly frozen in France, but comes also from abroad. In the breeding season of 2003, the foaling rates of mares inseminated with frozen semen were $64 \%$ for National Stud stallions, 62\% for private French breed stallions and 57\% for private foreign breed stallions (semen doses are mainly imported). In the same breeding season, the foaling rate was $64 \%$ for all the warm-blooded stallions in hand mating.

In this paper, a retrospective analysis of 20 years of practice in National Stud is presented, followed by a discussion on factors affecting fertility of frozen semen.

\section{Material and methods}

\subsection{General procedures}

Data were provided by the National Stud from 1985 to 2005. The stallions and mares were mainly of the "Selle-Français" warm-blooded breed. Stallions were selected according to criteria presented by Vidament et al. (2000b). Semen was frozen in autumn and winter according to different protocols (Palmer (1984) and derived procedures).

If not specified, milk in all these protocols was liquid UHT (Ultra Heat Treatment) skim milk. The INRA82 extender consisted of $0.5 \mathrm{~L}$ glucose-saline solution (138.73 mM glucose, 4.16 $\mathrm{mM}$ lactose, $2.52 \mathrm{mM}$ raffinose, $0.85 \mathrm{mM}$ sodium citrate dihydrate, $1.26 \mathrm{mM}$ potassium citrate, $20 \mathrm{mM}$ hepes) and 0.5 L milk with pH adjusted to 6.8 (Palmer, 1984). Extenders E1 (INRA 82 + centrifuged egg yolk 2\%, v/v) and E2 (E1+ glycerol, 2.5\%, v/v) were used. If not specified, all extenders contained 50,000 UI penicillin and $50 \mathrm{mg}$ gentamycin per liter. In one protocol, glutamine (50 $\mathrm{mM})$ was added to E2.

The semen was first diluted in E1, in E2 or in milk, centrifuged and frozen in E2 at a concentration of $75 \times 10^{6}$ spermatozoa/ml (no correction for sperm loss after centrifugation) to $100 \times 10^{6}$ spermatozoa/ml (correction of sperm loss since 1995$)$. Straws $(0.5 \mathrm{ml})$ were frozen at $-60^{\circ} \mathrm{C} / \mathrm{min}$ above liquid nitrogen vapor or in a programmable freezer (IMV, L'Aigle, France) at the same cooling rate.

At the first dilution and after the centrifugation, the temperature and extender differed among the protocols. Freezing protocols were named (Name XY/X' $Y^{\prime}$ ) according to the temperature $(\mathrm{X})$ and extender $(\mathrm{Y})$ at the first dilution and according to the temperature $\left(\mathrm{X}^{\prime}\right)$ and extender ( $Y^{\prime}$ ) used at the second dilution. The main protocols used were $37 \mathrm{E} 1 / 4 \mathrm{E} 2$ (Palmer, 1984) and 37 E1/22 E2 (Vidament et al., 2000a). At present, a new protocol 37 Milk/ 22 E2 is used (see below).

Selection of frozen ejaculates for insemination was based on 2 to 3 thawed straws, which were evaluated for motility either with a microscope (1985 to 1989) or with a computer-assisted motility analyzer (CASA) in a unique centre. Only ejaculates with post-thaw rapid motility higher than 35\% were selected. Rapid motility is the percentage of spermatozoa moving above a certain average path velocity (VAP) and is provided by the CASA analyzer. The VAP threshold for determining rapid motility was $30 \mu \mathrm{m} / \mathrm{sec}$ with the CASA HTM version 2000 (Hamilton Thorne Research, Beverly, MA, USA) (used from 1990 to 2000) (Palmer and Magistrini, 1992), 
but it was increased to $40 \mu \mathrm{m} / \mathrm{sec}$ once a new CASA analyzer (HTM-IVOS, version 10.9, Hamilton Thorn Research) was bought in 2001. More precisely for this IVOS system, parameter settings were: 30 frames acquired at 60 frames per second; minimum contrast 80 , minimum cell size 4 pixels; lower VAP cut-off $20 \mu \mathrm{m} / \mathrm{s}$; VAP cut-off for progressive and rapid cells $40 \mu \mathrm{m} / \mathrm{s}$; Straightness cut-off for progressive cells 80.

Freezability of the semen of a stallion was calculated by the proportion of the number of ejaculates selected after freezing-thawing over the total number of ejaculates.

In the insemination centres, mares were inseminated at the end of estrus with various regimes of inseminations before ovulation (according to the number of AI, of spermatozoa, and of days between inseminations). After thawing at $37^{\circ} \mathrm{C}$ for $30 \mathrm{sec}, 4$ or 8 straws were inseminated into the uterine body close to the cervix. Each year, foaling rate results were recorded and published by S.I.R.E. (data base listing all French horses), the foaling rate is the percentage of mares which delivered a foal or a foetus / number of inseminated or mated mares.

\subsection{Specific experiments or data analyses}

\subsubsection{First dilution in milk}

Bedford et al. (1995) observed a lower motility when non-centrifuged fresh semen was stored $24 \mathrm{~h}$ at $4^{\circ} \mathrm{C}$ in extender containing egg yolk compared to centrifuged semen (without seminal plasma) in the same extender suggesting a negative interaction between stallion seminal plasma and egg yolk. In the French freezing protocol, first dilution is performed in E1 containing $2.5 \%$ egg yolk. The aim of the 3 following experiments ( 2 preliminary and 1 field trial) was mainly to compare the effect of performing the first dilution at $37^{\circ} \mathrm{C}$ either in extenders without egg yolk (INRA82 or milk) or in E1, with a freezing protocol 37 Various Extenders/22E2. Since UHT milk is not sold in all countries, some scientists and veterinarians have asked us if the base extender INRA82 could be made with non-fat dry milk.

The objective of experiment 1 was to compare post-thaw motility of sperm initially diluted in either E1, INRA82 or milk. Semen from 6 Merens breed stallions (2 ejaculates per stallion) was divided in 3 parts and frozen after the first dilution at $37^{\circ} \mathrm{C}$ either in E1, INRA82 or in milk without antibiotics. Post-thaw motion characteristics (rapid motility and VAP) on 3 straws per ejaculate $\mathrm{x}$ treatment were measured by CASA.

In experiment 2, the same treatments were investigated as in experiment 1 except that a second control was used. In the control, extenders E1 and E2 were derived from INRA82 in which milk was replaced by non-fat dry milk (Sanalac ND) and apyrogenic water (E1S/E2S). Semen from 5 Welsh ponies (2 ejaculates per stallion) was divided in four parts and frozen and post-thaw motion characteristics (CASA: rapid motility and VAP, 3 straws / ejaculate $\mathrm{x}$ treatment) and viability (carboxyfluorescein diacetate (CFDA) and propidium iodide (PI)) (Harrisson and Vickers, 1990), using flow cytometry (Flow cytometer Facstar Plus, Becton Dickinson, San Jose, USA) (3 straws x 2 tubes per ejaculate x treatment) were measured.

The aim of experiment 3 (major field trial) was to compare initially diluting in E1 or in milk without antibiotics, on post-thaw sperm motility of numerous field stallions (winters 2000 to 2001 and 2001 to 2002) and to measure the field fertility of some of these stallions during the 2001 and 2002 breeding seasons. For each stallion, three ejaculates were frozen per week and the two freezing protocols were alternated every other week. Stallions were included in the comparison of post-thaw motility, if more than 2 ejaculates per protocol were frozen in the subsequent week. Then, after freezing and post-thaw selection, semen was used in almost 90 different insemination centers without knowledge of the freezing protocol. Mares were 
inseminated every $24 \mathrm{~h}$ until ovulation, most mares were inseminated 2 times during the same estrus with $400 \times 10^{6}$ total spermatozoa at each AI. They were examined for pregnancy between 13 and 35 days postovulation. Only stallions with fertility data for 6 or more cycles per freezing protocol were included in the fertility analysis.

\subsubsection{Relationship between some characteristics of spermatozoa and fertility of frozen semen}

Data were obtained from breeding records in 1999. Data on cycles $(n=626)$ were included in the analysis if: (1) pregnancy result and ejaculate number were known, (2) only one ejaculate was used for all AIs of the cycle and (3) the ejaculate was frozen with the protocol 37E1/22E2 in 1999 or before. In a file, each cycle, positive or negative after a pregnancy diagnosis before 25 days, was associated with the values of 3 criteria measured on the corresponding ejaculate during the control analysis made at selection (rapid motility (Rapid \%), velocity (VAP) and amplitude of lateral displacement (ALH)). Then, for each criterion, lines were ranked by increasing value of this criterion and assembled in classes with more or less the same number of cycles. Then fertility was calculated by class (positive cycles / total cycles of the class) and correlation between class value and fertility was calculated using the nonparametric coefficient of Spearman.

\subsubsection{Insemination strategy}

A comparison was conducted in field centres in 1994 (limited number of AI centres) and in 1995 (all centres) between the dose regimen " $300 \& 150$ x 24 h" (first insemination with $300 \times 10^{6}$ spermatozoa followed at 24-h intervals by additional AI(s) with $150 \times 10^{6}$ until ovulation) and the dose regimen " 300 x 24 h" (dose of $300 \times 10^{6}$ spermatozoa every $24 \mathrm{~h}$ until ovulation). Mares were inseminated during the first cycle with one dose regimen and during the second cycle (if non pregnant) with the other. Only cycles in which mares were inseminated with semen frozen with the same protocol (37E1/4E2) without correction of sperm losses were compared.

\subsubsection{Statistical analyses}

For Experiments 1 and 2, the model was balanced. General differences between means were tested by an ANOVA (GLM procedure of SAS; SAS Institute Inc., Cary, NC, USA) considering effects of protocol, stallion and ejaculate within stallion. For Experiment 3, the model was an unbalanced comparison of two protocols between ejaculates within stallions. General differences between means were tested by a factorial analysis for unbalanced data (GLM procedure of SAS) considering effects of protocol and stallion. Chi-square test was used to compare the percentages (per-cycle pregnancy rate) in Experiment 3. Statistical significance was considered at $P<0.05$.

\section{Results}

\subsection{Evolution in National Stud between 1985 and 2005}

Changes in freezing protocol, semen production, insemination strategies and fertility of frozen semen in National Stud (1985-2005) are presented in Tables 1 and 2. Note for Table 2 that: 1) this table is not directly linked to Table 1 , because at least half of the used semen in one year was frozen in the previous winter, the rest was stored for 1 or more years; 2 ) it is not known to which extent the AI recommendations were followed by veterinarians and technicians.

There has been a considerable development in the use of frozen semen in the National Stud that can be described in 4 steps: 
- 1985-1988: beginning of commercial use of frozen semen with encouraging results (50\% ejaculates selected after freezing, 33\% per-cycle pregnancy rate, 60 to $62 \%$ foaling rate similar to fresh semen foaling rate), one freezing center, less than 10 AI centers and 90 to 300 inseminated mares per year

- 1989-1994: lowered results ( $\leq 40 \%$ ejaculates selected after freezing, $\leq 30 \%$ per-cycle pregnancy rate, $\leq 50 \%$ foaling rate) with the growing production ( 4 freezing centres) and geographic dispersion in the use of frozen semen (40 AI centers, 300 to 400 mares)

- 1995-1998: improved results due to modifications in the freezing protocol and insemination strategy (75\% ejaculates selected, 50\% per-cycle pregnancy rate, 70\% foaling rate), which resulted in an increase in number of ejaculates frozen (>950) and of the number of inseminated mares $(>700)$

— 1999-2005: stabilization of the results (85\% ejaculates selected after freezing, 46 to $48 \%$ pregnancy rate per cycle, $64 \%$ foaling rate) simultaneously with a high increase in number of ejaculates frozen (>1850) and of number of inseminated mares (up to 2000) in >90 national stud centres and in 65 private centres.

\subsection{Progress in semen processing and in stallion management}

From these data, proper comparisons between some freezing protocols have been published previously. The freezing protocol of 37E1/22E2, compared to 37E1/4E2, improved spermatozoal recovery after centrifugation, post-thaw motility (40\% vs 36\%) and pregnancy rate per cycle (56\% vs 42\%) (Vidament et al., 2000a). Freezing protocol 22E2/22E2 compared to 37E1/22E2 improved motility very slightly but not fertility, and freezing protocol 37E1/22E2Glu (E2 + $50 \mathrm{mM}$ glutamine) consistently improved motility and velocity but not fertility as compared to 37D1/22D2 (Vidament et al., 2001).

For the experiments with the first dilution in milk, in experiment 1 , rapid motility was similar when semen was frozen after the first dilution at $37^{\circ} \mathrm{C}$ in E1 (28\%), INRA82 (25\%) or in milk without antibiotics (29\%) $(\mathrm{P}=0.27)$ (VAP for the three extenders was: 69, 67 and 69 $\mu \mathrm{m} / \mathrm{sec}$, respectively, $\mathrm{P}=0.49$ ). In experiment 2 , motility, velocity and viability were very similar for sperm in the various extenders (Table 3). In experiment 3, post-thaw rapid motility, velocity and per-cycle pregnancy rate were similar for the 2 extender protocols (Table 4). However, the number of straws per ejaculate was lower $(\mathrm{P}<0.05)$ with milk dilution than with $\mathrm{E} 1$ dilution. The stallions were ranked in 5 groups according to their mean post-thaw sperm motility after freezing with the 37E1/22E2 protocol. For stallions $<35 \%$ post-thaw motility, milk dilution resulted in higher post-thaw motility than with E1 dilution (33\% (69 ejaculates) versus 27\% (70 ejaculates) ( 9 stallions, $\mathrm{P}<0.05)$ ). There was no difference in post-thaw motility between the two freezing protocols in the other groups.

\subsection{Evaluation of semen}

A relationship was demonstrated between rapid motility and fertility $(\mathrm{P}<0.01)$ (Figure 1$)$. Pregnancy rate per cycle was $43 \%(\mathrm{n}=193)$, when motility was less than $45 \%$, and $52 \%$ when motility was over this value $(\mathrm{n}=433)(\mathrm{Chi}$ square $=4.33, \mathrm{P}<0.05)$. Similarly, a relationship was found between VAP and fertility $(\mathrm{P}<0.01)$ (Figure 2). Pregnancy rate per cycle was $45 \%(\mathrm{n}=355)$ when VAP was $<66 \mu \mathrm{m} / \mathrm{sec}$ and $54 \%$ when VAP was over this value $(\mathrm{n}=271)($ Chi square $=$ 4.98, $\mathrm{P}<0.05)$. No relationship was found between ALH and fertility.

\subsection{Progress in insemination strategy}


During the first years of data collection, a dose of $300 \times 10^{6}$ every $48 \mathrm{~h}$ was decreased to $150 \times 10^{6}$ every $24 \mathrm{~h}$; the AI dose for fresh semen was also reduced in the National Stud from $400 \times 10^{6}$ to $200 \times 10^{6}$ total sperm. Palmer and Magistrini (1992) observed no differences in fertility based on breeding records from 1986 to 1990 between the two doses but pointed out an improvement in fertility when 2 AI were used instead of 1 AI. A detailed analysis of breeding records from 1991 to 1995 confirmed this beneficial effect of multiple AI and showed a tendency for better results, when the last AI dose was $300 \times 10^{6}$ spermatozoa $24 \mathrm{~h}$ before ovulation (Vidament et al., 1997).

The comparison between the two dose regimens demonstrated that per-cycle pregnancy rates were higher $(\mathrm{P}<0.05)$ for mares inseminated twice with $300 \times 10^{6}$ sperm at $24 \mathrm{~h}$ intervals (“300 x $24 \mathrm{~h}$ ”) than for those inseminated initially with $300 \times 10^{6}$ then with $150 \times 10^{6}$, 24h later (“300 \& 150 x 24 h”) (Table 5).

\subsection{Results with the present system}

The present French system is described in detail in Table 6.

In frozen semen, the mean final glycerol concentration was $2.1 \%$ and the average proportion of seminal plasma was 4.4\%. Data on stallions whose semen was frozen in years 2003 to 2005 were pooled (freezing protocol: 37Milk/22E2). Among the population of stallions with $\geq 4$ ejaculates frozen during one year, the distribution of the various mean rapid motility is shown in figure $2(\mathrm{n}=344$ stallions). The majority of stallions ( $80 \%$ ) had a mean post-thaw motility higher than $40 \%$. The distribution of the number of stallions with ejaculates of various freezability is depicted in Figure 3. Of the stallions, 5, 4, 5, 21 and 64\% had a semen freezability of 0 to 10,10 to 33, 33 to 60,60 to 90 and over $90 \%$, respectively. Thus, only $9 \%$ of the stallions had semen that could not be frozen (less than $33 \%$ ejaculates selected) with the present freezing protocol.

For ejaculates frozen in years 2003 to 2005 (Table 7), the mean post-thaw rapid motility was $50 \%$ and progressive motility approximately $38 \%$ in all ejaculates, and $55 \%$ and $42 \%$ in selected ejaculates, respectively. Around 80 to 85 straws were frozen from each ejaculate. As 48 straws were reserved for a mare per season, frozen spermatozoa for 1.4 to 1.5 mares per season were produced from each selected ejaculate.

When the recommended dose rate of AI changed in 1995 from " $300 \& 150$ x 24 h" to "300 x 24 h", the number of straws per mare changed from 48 to 56 straws. Since the mean number of straws used was regularly 32 to 35 straws per mare in 1996 to 1998, the number of straws per mare was reduced to 48 in 1999. More spermatozoa were used per AI, but fewer cycles per pregnancy were used, since the insemination was more fertile.

\section{Discussion}

\subsection{Semen processing and stallion management}

During 1985-2005, the major modification that improved motility, freezability and fertility of stallions was the adoption of the 37E1/22E2 protocol (Vidament et al., 2000a). Fertility and motion characteristics of semen first diluted either in E1 or in milk were similar. During the first dilution of semen in E1 (the average proportion of seminal plasma was 25\%), the negative interaction between egg yolk and seminal plasma described by Bedford et al. (1995) could have reduced the quality of spermatozoa after freezing. This was not the case for the majority of the stallions, since the sperm were in the first extender a short time (30 min). 
Surprisingly, the number of straws was slightly reduced with milk. Constituents of E1 not present in milk (some sugars, salts or more likely egg yolk) could explain this effect. Moreover, the first dilution in milk is a simplification of the freezing protocol, since it saves time (fabrication and storage of extender) and money; the lower number of straws has been considered by the technicians as a minor drawback.

With the 37Milk/22E2 protocol, the post-thaw motility and the rate of selected ejaculates was very high, much higher than that described generally in the literature, since $64 \%$ of stallions had more than $90 \%$ of their ejaculates selected after freezing for use on mares. This is due to an efficient freezing protocol (high mean motility after thawing), but also to the management of stallions whose semen froze poorly. These stallions have to be rejected rapidly from production: rejection after six low quality ejaculates, especially if the results were the same the year before. This rule was insufficiently applied in the National Stud before 1994 and led to a catastrophic low mean rate of selected ejaculates. When the 37E1/22E2 and 37Milk/22E2 protocols were used, the proportion of stallions with unfreezable sperm (i.e. with less than $33 \%$ ejaculates selected after post-thawing control) was low (9 to 15\%), much lower than with the 37E1/4E2 protocol (49\%). Other authors have previously obtained high freezability results: 11 to $14 \%$ of stallions with unfreezable sperm and 83 to $90 \%$ of selected ejaculates post-thaw from the remaining stallions (Salazar-Valencia, 1983; Müller, 1982) but after a high selection of stallions and ejaculates before freezing (Müller, 1982).

Effect of some modifications of the freezing protocol on sperm quality cannot be estimated since no comparison was done before and after the modification. This was the case for the slight centrifugation of egg yolk (1992), correction for sperm loss (1995) and the use of apyrogenic water instead of charcoal demineralized or distilled water in the extenders (1995). Nevertheless, correction for sperm loss permitted a standardisation of the number of sperm per straw and an increase of the number of sperm per straw.

\subsection{Glycerol is essential for cryopreservation but limiting for fertility}

Glycerol is the essential cryoprotectant in all conventional extenders for freezing stallion

spermatozoa. During freezing, spermatozoa are protected since glycerol reduces concentration of extracellular salts during the dehydration time and raises the percentage of unfrozen water at any given temperature. Spermatozoa are apparently sequestered into narrow channels of unfrozen water between large ice crystals (Amann and Pickett, 1987).

The concentration of glycerol varies strongly (from 1- to 3-fold) in the equine freezing extenders: 2.5\% (Palmer, 1984), 3\% (Wilhelm et al., 1996), 3.5\% (Tischner, 1979; Müller, 1987; Burns, 1992), 4\% (Cochran et al., 1984; Heitland et al., 1996), 5\% (Nishikawa, 1975; Martin et al., 1979) and 7\% (Pace and Sullivan, 1975). The optimum glycerol concentration for maximal post-thaw motility of equine spermatozoa has not been clearly evidenced, and could differ according to the extender composition (Ecot et al., 2000). Another confusing point is that concentration of glycerol in papers is very often indicated in the freezing extender and not in the processed semen (final concentration). This final concentration depends on the dilution rate of the freezing extender by the pellet, and it is not always possible to calculate the level with the information given in the paper.

In INRA82 extender, the optimal glycerol concentration for maximal post-thaw motility is around 2-3\% (final concentration) (Ecot et al., 2000; Vidament et al., 2001; Vidament et al., 2002). In the most commonly used extender, Lactose-Glucose EDTA (Martin et al., 1979), this optimal concentration could be 4\% (extender concentration) (Cochran et al., 1984; Cristanelli et 
al., 1985). In Kenney freezing extender, Burns and Reasner (1995) reported that the maximal post-thaw motility improvement was obtained between 0 and $2 \%$ glycerol concentration (extender concentration).

Compared to fresh semen without glycerol, lower fertility in mares has been observed when equine fresh semen was prepared with glycerol at concentrations of $4 \%$ (final concentration, Bedford et al., 1995), 5\% (extender concentration, Loomis et al. 1983), 4.8\% (final concentration, Vidament et al., 2005) and 7\% (extender concentration, Pace and Sullivan, 1975; Demick et al., 1976). However, based on our 1985 to 2005 data with frozen semen, 2.5\% glycerol (in freezing extender) routinely provided satisfactory per-cycle pregnancy rate. In limited studies, we observe a similar per-cycle pregnancy rate when semen was frozen with 2 or 3\% glycerol (final concentration) (Vidament et al., 2002) and when fresh semen was prepared and cooled with 2.2 (53\%) or 3.5 (53\%) glycerol (final concentration) (Vidament et al., 2005).

In extensive studies where fertility per cycle was reported to be over $40 \%$ in more than 100 cycles and in which characteristics of freezing processing are known, final glycerol concentration was low in most cases: less than 2.5\% (Sieme et al., 2003 and our data), less than 3.5\% (Müller, 1987), less than 4\% (Salazar-Valencia, 1983, calculated data) and less than 5\% (Nishikawa, 1975). A contraceptive effect of glycerol is well documented in hens, even though glycerol is the most successful cryoprotectant for the spermatozoa in this species (reviewed by Hammerstedt and Graham, 1992). Glycerol has also a certain contraceptive effect in equine species, this effect seems to be stronger in asine species (Vidament et al., 2005).

Glycerol is difficult to measure precisely because of its high viscosity, so mistakes in the measuring of glycerol volumes are possible. Osmotic pressure measurements during preparation of extender could help to adjust correctly this concentration.

A compromise should be found between the cryoprotective effect and the negative effect on fertility. A low level of glycerol in frozen semen should be considered as a quality factor for fertility if a minimum post-thaw motility is obtained. Finally, considering both motility and fertility, the recommended glycerol final concentration is 2.5 to $3.5 \%$.

Other cryoprotectants like ethylene glycol and dimethylformamide (DMF) have been proposed recently for freezing equine semen (Medeiros et al., 2002; Vidament et al., 2002; Mantovani et al., 2002; Squires et al., 2004). However, more extensive studies including fertility trials are needed before considering replacing glycerol.

\subsection{Base extender}

Comparisons between freezing extenders for stallion semen are poorly documented. Mainly 3 extenders are presently used: Lactose-Glucose EDTA Freezing Extender (FE) (Lactose - 25\% glucose EDTA solution - 20\% egg yolk - 5\% glycerol; Martin et al., 1979) modified by Cochran et al. (1984) (4\% glycerol), INRA82 FE (INRA82 + 2\% egg yolk $+2.5 \%$ glycerol = E2 in our experiments; Palmer, 1984) sometimes also named SMEY Extender by other authors (Heitland et al., 1996) and Kenney FE (Kenney extender + 4\% clarified egg yolk $+3.5 \%$ glycerol; Burns, 1992). Only a few comparisons have been made between these extenders and only one comparison of fertility has been done.

Post-thaw motility was higher when semen was processed in INRA82 FE than in Lactose-Glucose EDTA FE (the two extenders contained 4\% egg yolk and 4\% glycerol) (Heitland et al., 1996). Post-thaw motility was higher when semen was processed in a modified Lactose-Glucose EDTA in which the 25\% glucose EDTA solution was replaced by $25 \%$ of Kenney extender than in the original Lactose-Glucose EDTA FE (Braun et al., 1995; Alghamdi 
et al. 2002; Schembri et al, 2003). In the above-modified Lactose-Glucose EDTA FE, the percentages of acrosome reaction and capacitated sperm were higher if Kenney extender contained bicarbonate (Schembri et al., 2003). In our laboratory, post-thaw motility was higher when semen was frozen in Kenney FE (with bicarbonate, 3.5\% glycerol, 4\% egg yolk) than in INRA82 FE (2.5\% glycerol) (Ecot et al., 2000). However, the percentage of intact acrosomes was lowered for sperm frozen in Kenney FE and per-cycle pregnancy rate was clearly reduced with sperm prepared in Kenney FE (38\%) compared to INRA82 FE (63\%) (Ecot et al., 2001).

In conclusion, although Kenney FE alone or mixed with Lactose-Glucose EDTA FE results regularly in higher motility compared to the other two extenders (Lactose-Glucose EDTA FE and INRA82 FE), there is indication of lowered fertility in some conditions. This could be due to the presence of bicarbonate in some formulae of Kenney; bicarbonate induces capacitation in spermatozoa of different species including the horse (for review: Gadella et al., 2001). Capacitation occurred rapidly in Kenney extender during storage of fresh semen (Pommer et al., 2002).

\subsection{Estimation of quality of frozen semen: value of motility}

Numerous investigators have attempted to find different criteria post-thaw that could best predict fertility of frozen semen, but very few studies are available with a sufficient number of stallions or mares (Samper et al., 1991; Kirk et al., 2005). Motility is the simplest to perform. In the analysis reported here, a relationship was found between the two sperm motion measurements, rapid motility and velocity, and the fertility of corresponding cycles. However, for velocity, the slope of the curve was so flat that this relationship cannot be used for selecting ejaculates for insemination. For rapid motility, the relationship to fertility was clearer.

In 1998, the analysis was done in a similar manner, but only rapid motility was used. The same type of result was found but it was non-significant: $45 \%$ fertility ( $n=359$ cycles) when motility was less than $45 \%$ and $50 \%(n=488)$ when motility was higher than $45 \%(P=0.15)$.

Nevertheless, all these data permit us to conclude that there is a relationship between post-thaw motility and fertility of frozen semen, at least among ejaculates frozen by the same technique and used in a similar manner. So the selection by this criterion is justified. However, when semen is frozen using different protocols, this relationship may no longer exist because other components of spermatozoa can react differently to various extenders, or various cooling curves.

\subsection{Insemination strategy}

In some countries, mares bred with frozen semen are examined 4 to 6 times per day and inseminated immediately before or within $6 \mathrm{~h}$ post-ovulation. This is based on the idea that frozen-thawed sperm do not survive long in the mare's reproductive tract. Also, stallion owners provide only limited doses of frozen semen for each mare, with sometimes no precise indication of the number of sperm and the quality of semen in the straws. Moreover, there is no international agreement on the minimum number of frozen sperm that should be sold for a cycle or for a mare per season.

Because sufficient numbers of straws are available in the French system (6 doses of $400 \mathrm{x}$ $10^{6}$ total spermatozoa, i.e. 48 straws), mares are examined once a day, when a preovulatory follicle is present, and inseminated every $24 \mathrm{~h}$ until ovulation. Fertility is improved when the mares are inseminated twice $24 \mathrm{~h}$ apart and before ovulation compared to once (Palmer and Magistrini, 1992; Vidament et al., 1997). 
In extensive studies where fertility per cycle was reported to be over $40 \%$ in more than 100 cycles, either mares were intensively monitored around ovulation and inseminated once (Salazar-Valencia, 1983; Samper et al., 1991; Darenius, 1999; Barbacini et al., 2003) or mares were monitored and inseminated every $24 \mathrm{~h}$ until ovulation (our data and those of Müller (1987)). The major drawback of post-ovulation AI is the increased rate of embryonic loss, as it has been demonstrated with fresh semen (Woods et al., 1990).

These two insemination strategies have been compared recently. Squires et al. (2003) reported similar per-cycle pregnancy rates where mares received either 2 AI of frozen sperm 24 and $40 \mathrm{~h}$ after administration of hCG (mares examined once a day) or 1 AI after ovulation (mares examined 3-6 times a day). Sieme et al. (2003) analyzed the effect of multiple AI versus single AI on fertility of frozen semen and concluded that 1) high fertility could be obtained if mares are inseminated once $12 \mathrm{~h}$ before to $12 \mathrm{~h}$ after ovulation, 2) multiple insemination increases the probability to inseminate during this optimal window and 3) the choice between the two AI regimes (one AI, frequent mare examinations versus multiple AI, examination once per $24 \mathrm{~h}$ ) depends largely on the balance between the cost of the semen per dose versus the costs of insemination and veterinary attention.

The means of improving fertility with the multiple insemination are: increasing the total number of spermatozoa available for the mare, increasing stimulation of the genital tract, and increasing the variability of the spermatozoa population within the female genital tract by frequent insemination of freshly thawed sperm. However, 4 inseminations of $100 \times 10^{6}$ total spermatozoa each, during $24 \mathrm{~h}$, with the last AI $5 \mathrm{~h}$ before ovulation, resulted in lower fertility than only 1 insemination with $400 \times 10^{6} 12$ h before ovulation (Clément et al., 2005).

Another confusing factor when comparing different studies is that most authors express sperm numbers in progressively motile spermatozoa (pms) without giving the motility value, whereas other workers use the total number. The tendency for higher fertility observed when the mare has received an insemination dose of $300 \times 10^{6}$ total sperm per AI than $150 \times 10^{6}$, $24 \mathrm{~h}$ before ovulation (Vidament et al., 1997) has been confirmed (trial 1994 and 1995). As most mares in our data received $2 \mathrm{AI}$, one can consider that fertility was higher when mares received $600 \times 10^{6}(2 \times 300)$ than $450 \times 10^{6}$ (300 then 150) total spermatozoa. So until the definitive adoption of the dose of $300 \times 10^{6}$ every day in 1996, and subsequently $400 \times 10^{6}$ every day after correction of sperm losses, the mares in our studies received regularly an insufficient number of spermatozoa. This could explain a part of the very low results observed from 1989 to 1994.

Amann and Pickett (1987) have suggested that maximum fertility for the stallion is a function of number of spermatozoa inseminated until a critical number is reached at which point fertility would not increased. For equine frozen semen inseminated into the uterine body, this critical value has not been determined yet: ranges between $175 \times 10^{6}$ motile spermatozoa (Volkman and Zyl, 1987) and $320 \times 10^{6}$ motile spermatozoa (Leipold et al., 1998), or between $450 \times 10^{6}$ total spermatozoa (our present data) and $800 \times 10^{6}$ total spermatozoa (Samper, 1995). So this number could be around $250 \times 10^{6}$ motile i.e. $750 \times 10^{6}$ total spermatozoa since most often post-thaw motility is 33 to $40 \%$ in most papers.

In extensive studies where fertility per cycle was reported to be over $40 \%$ in more than 100 cycles and in which characteristics of semen are known: the number of spermatozoa per AI have been equal or greater than $400 \times 10^{6}$ total (Salazar-Valencia, 1983), $240 \times 10^{6}$ motile (Loomis, 2001), 2 times $400 \times 10^{6}$ total (our data) and $700 \times 10^{6}$ total spermatozoa (Nishikawa, 1975; Müller, 1987; Samper et al., 1991; Darenius, 1999; Sieme et al., 2003). 
In conclusion, the number of frozen sperm usually used per cycle seems very near this critical number. It is important for the mare owners to have the possibility to purchase a number of spermatoza above this value rather than below. Nevertheless, this critical number of spermatozoa is dependent on the stallion, the post-thaw quality of sperm, the extender (glycerol concentration), but certainly dependent also on the time between AI and ovulation and on the insemination site.

To insure a proper number of spermatozoa for the mares, it is necessary to produce straws with a fixed and known concentration. It is, therefore, necessary to evaluate and correct sperm losses after centrifugation. These losses are reported to be 10 to $40 \%$, depending on temperature, extender, volume, centrifugation time, centrifugation force and volume of supernatant left above pellet (Pickett et al., 1975; Cochran et al., 1984; Volkman and van Zyl, 1987, Heitland et al., 1996; Vidament et al., 2000). In milk, the recovery was less than in extender E1 in the experiments presented in this paper. Different techniques of cushion under the pellet have been proposed but they have never permitted a total recovery of spermatozoa (Cochran et al., 1984; Volkman et al., 1987). Recently, a dense medium was proposed as a cushion and resulted in a total recovery of sperm if clear extender is used (Ecot et al., 2005).

Numerous studies with low doses of spermatozoa and/or deep uterine AI performed either with an endoscope or by a rectally-guided approach have been conducted recently with fresh or frozen equine semen and have demonstrated that pregnancies can be obtained with very low doses in very strict conditions (reviews: Ball, 2004; Morris, 2004). Unfortunately, some of them are inconclusive because: 1) the comparison between groups is confounded with too many factors, 2) numbers of cycles and stallions are insufficient, 3) freezing technique is unspecified or invalid. There is a lack of comparison between these techniques and well established standard procedures (Sieme et al., 2004). We have observed that per-cycle pregnancy rate was reduced when $50 \times 10^{6}$ total frozen spermatozoa were deposited $12 \mathrm{~h}$ before ovulation either into the uterine body (26\%) or into the tip of the horn ipsilateral to the preovulatory follicle by a rectallyguided approach (25\%), compared to $400 \times 10^{6}$ total frozen spermatozoa into the uterine body (46\%) (Clément et al., 2005). Sieme et al. (2004) found no difference in fertility between $100 \mathrm{x}$ $10^{6}$ total spermatozoa (frozen in modified INRA82 $+2 \%$ egg yolk $+2.5 \%$ glycerol) inseminated into the uterine body (per-cycle pregnancy rate $43 \%$ ), into the tip of the horn by a rectally-guided approach (45\%) or by endoscopy (46\%) and $800 \times 10^{6}$ total spermatozoa inseminated into the uterine body (43\%), in all cases, the unique AI was performed 6 hours before ovulation. In these latter two papers, insemination into the tip of the horn did not improved fertility, compared to similar numbers of spermatozoa inseminated into the uterine body.

\subsection{Proposal for uniform information about frozen semen}

In European Community, there are no particular regulations on quality and quantity of equine frozen semen, except for a sanitary point of view. So mare owners need technical information on the frozen semen they want to purchase. The above discussion has focussed on some important points that affect fertility: the total number of sperm available for a mare per season (number of spermatozoa per AI dose $\mathrm{x}$ number of AI doses), the post-thawing motility and the glycerol concentration in the straw. Unfortunately, the idea of using low doses of frozen semen has spread widely and could reduce fertility. With the French system, a stallion on the average produces a mean of 82 straws ( $\left.50 \times 10^{6} \mathrm{sperm} / \mathrm{straw}\right)$ per ejaculate. During one week (3 ejaculates produced, $85 \%$ ejaculates selected), the production is 209 straws ( $82 \times 3 \times 0.85)$. When 48 straws (6 doses of 8 straws) are reserved for a mare per season, 3 ejaculates provide 
enough sperm for insemination of 4.35 mares. If a stallion owner sells two straws of $50 \times 10^{6}$ total sperm per mare per season, in 3 ejaculates, a stallion can provide enough semen for 105 mares. It seems to be a rather misleading practice. To keep $2.4 \times 10^{9}$ total sperm $(6 \times 8$ straws (number of straws per insemination)) for a mare per season does not seem exaggerated, since for most stallions, it represents only $33 \%$ or less of an ejaculate.

I suggest a codification for equine frozen offered for sale on the breeding market: the first letter describes the number of spermatozoa available per mare per season, the second letter describes the post-thaw motility and the third letter describes the final glycerol concentration (Table 8). For instance, all the semen sold by French National Stud is A***AA. This codification would indicate to the owners the easiness to obtain pregnancy with the frozen semen they purchase. A form like the one presented in Table 9 should come with the straws. I hope that this codification could be discussed between equine semen experts and be modified, if necessary, and could help in equine semen exchanges.

\section{Acknowledgements}

To all people in the freezing, control and insemination centers of French National Stud (Les Haras Nationaux) for applying the protocols and providing information every year.

To J.M. Yvon for technical assistance in Nouzilly, to all people for computerizing the data each year and to people from the experimental centres of Nouzilly, Chamberet and Le Pin (freezing experiments).

To M. Magistrini, H. Busson-Rousset, F. Clément, P. Ecot and E. Palmer for constructive scientific discussions.

To S.I.R.E. for providing information

To Y. Le Vern and D. Kerboeuf (flow cytometry service in Nouzilly) for performing the cytometry analyses.

\section{References}

Alghamdi, A.S., Troedsson, M.H., Xue, J.L., Crabo, B.G., 2002. Effect of seminal plasma concentration and various extenders on postthawmotility and glass wool-Sephadex filtration of cryopreserved stallion semen. Am. J. Vet. Res. 63, 880-885.

Amann, R.P., Pickett, B.W., 1987. Principles of cryopreservation and a review of cryopreservation of stallion spermatozoa. Equine Vet. Sci. 7, 145-173.

Ball, B.A., 2004. Hysteroscopic and low dose insemination techniques in the horse. In: Recent Advances in Equine Reproduction. International Veterinary Information Service Ithaca, New York, USA. http://www.ivis.org/advances/Reproduction_Ball/ball3/chapter_frm.asp?LA=1

Barbacini, S., Necchi, D., Zavaglia, G., Squires, E.L., 2003. Retrospective study on the incidence of postinsemination uterine fluid in mares inseminated with frozen-thawed semen. Equine Vet. Sci. 23, 493-496.

Bedford, S.J., Jasko, D.J., Graham, J.K., Amann, R.P., Squires, E.L., Pickett, B.W., 1995. Effect of seminal extenders containing egg yolk and glycerol on motion characteristics and fertility of stallion spermatozoa. Theriogenology 43, 955-967.

Braun, J., Hochi, S., Oguri, N., Sato, K., Torres-Boggino, F., 1995. Effect of different protein supplements on motility and plasma membrane integrity of frozen-thawed stallion spermatozoa. Cryobiology 32, 487-492. 
Burns, P.J., 1992. Modification of Kenney's extender for cryopreservation of equine spermatozoa. Proceedings 12th International Congress on Animal Reproduction, 4, abstract $\mathrm{n}^{\circ} 536$.

Burns, P.J., Reasner, D.S., 1995. Computerized analysis of sperm motion: effects of glycerol concentration on the cryopreservation of equine spermatozoa. Equine Vet. Sci. 15, 377-380.

Clément, F., Duchamp, G., Larry, J.L., Vidament, M., 2005. Effects of frequency of insemination, number of spermatozoa and insemination site on fertility of equine frozen semen. Proceedings 4th International Symposium on Stallion Reproduction, October 2123, Hannover, Germany, accepted abstract.

Cochran, J.D., Amann, R.P., Froman, D.P., Pickett, B.W., 1984. Effects of centrifugation, glycerol level, cooling to $5^{\circ} \mathrm{C}$, freezing rate and thawing rate on the post-thaw motility of equine sperm. Theriogenology 22, 25-35.

Cristanelli, M.J., Amann, R.P., Squires, E.L., Pickett, B.W., 1985. Effects of egg yolk and glycerol level in lactose-EDTA-egg yolk extender and of freezing rate on the motility of frozen-thawed stallion spermatozoa. Theriogenology 234, 25-38.

Darenius, K., 1999. Fertility data in the horse and the occurrence of pregnancy and neonatal loss in relation to breeding method. CRB-Special Symposium: “Aspects of Equine Reproduction”, SLU.

Demick, D.S., Voss, J.L., Pickett, B.W., 1976. Effect of cooling, storage, glycerolization and spermatozoal numbers on equine fertility. J. Anim. Sci. 43, 633-637.

Ecot, P., Arnaud, G., Moy, A., Daels, P., Magistrini, M., Vidament, M., 2001. Comparison of fertility and post-thaw semen criteria of stallion semen frozen in two different extenders. In: Squires E.L. (Ed.), Proceedings 3rd International Symposium on Stallion Reproduction. Anim. Reprod. Sci. 68, 356-358.

Ecot, P., Decuadro-Hansen, G., Delhomme, G., Vidament, M., 2005. Evaluation of a cushioned centrifugation technique for processing equine semen for freezing. Proceedings 4th International Symposium on Stallion Reproduction, October 21-23, Hannover, Germany, accepted abstract.

Ecot, P., Vidament, M., de Mornac, A., Perigault, K., Clément, F., Palmer, E., 2000. Freezing of stallion semen: interactions among cooling treatments, semen extenders and stallions. J. Reprod. Fertil., Suppl. 56, 141-150.

Gadella, B.M,. Rathi, R., Brouwers, J.F., Stout, T.A., Colenbrander, B., 2001. Capacitation and the acrosome reaction in equine sperm. Anim. Reprod. Sci. 68, 249-265.

Hammerstedt, R.H., Graham, J.K., 1992. Cryopreservation of poultry sperm: the enigma of glycerol. Cryobiology 29, 26-38.

Harrison, R.A., Vickers, S.E., 1990. Use of fluorescent probes to assess membrane integrity in mammalian spermatozoa. J. Reprod. Fertil. 88, 343-352.

Heitland, A.V., Jasko, D.J., Squires, E.L., Graham, J.K., Pickett, B.W., Hamilton, C., 1996. Factors affecting motion characteristics of frozen-thawed stallion spermatozoa. Equine Vet. J. 28, 47-53.

Kirk, E.S., Squires, E.L., Graham, J.K., 2005. Comparison of in vitro laboratory analyses with the fertility of cryopreserved stallion spermatozoa. Theriogenology (accepted, available on line at www.sciencedirect.com)

Leipold, S.D., Graham, J.K., Squires, E.L., McCue, P.M., Brinsko, S.P., Vanderwall, D.K., 1998. Effect of spermatozoal concentration and number on fertility of frozen equine semen. Theriogenology 49, 1537-1543. 
Loomis, P.R., Amann, R.P., Squires, E.L., Pickett B.W., 1983. Fertility of unfrozen and frozen stallions spermatozoa extended in EDTA-Lactose-egg yolk and packaged in straws. J. Anim. Sci. 56, 687-693.

Loomis, P.R., 2001. The equine frozen industry. Anim. Reprod. Sci. 68, 191-200.

Mantovani, R., Rora, A., Falomo, M.E., Bailoni, L., Vincenti, L., 2002. Comparison between glycerol and ethylene glycol for the cryopreservation of equine spermatozoa: semen quality assessment with standard analyses and with the hypoosmotic swelling test. Reprod. Nutr. Dev. 42, 217226.

Martin, J.C., Klug, E., Gunzel, A., 1979. Centrifugation of stallion semen and its storage in large volume straws. J. Reprod. Fertil., Suppl. 27, 47-51.

Medeiros, A.S.L., Gomes, G.M., Carmo, M.T., Papa F.O., Alvarenga M.A., 2002. Cryopreservation of stallion sperm using different amides. Theriogenology 58, 273-276.

Morris, L.H., 2004. Low dose insemination in the mare: an update. Anim. Reprod. Sci. 82-83, 625-632.

Müller, Z., 1987. Practicalities of insemination of mares with deep frozen semen. J. Reprod. Fertil., Suppl. 35, 121-125.

Nishikawa, Y., 1975. Studies on the preservation of raw and frozen horse semen. J. Reprod. Fertil., Suppl. 23, 99-104.

Pace, M., Sullivan, J.J., 1975. Effect of timing insemination, numbers of spermatozoa and extender components on the pregnancy rate in mares inseminated with frozen semen. J. Reprod. Fertil., Suppl. 23, 115-121.

Palmer, E., 1984. Factors affecting stallion semen survival and fertility. Proceedings 10th International Congress on Animal Reproduction and Artificial Insemination, pp. 377-378.

Palmer, E., Magistrini, M., 1992. Automated analysis of stallion semen post-thaw motility. Acta Vet. Scand., Suppl. 88, 137-152.

Pickett B.W., Sullivan J.J., Byers W.W., Pace M.M., Remmenga E.E., 1975. Effect of centrifugation and seminal plasma on motility and fertility of stallion and bull spermatozoa. Fertil. Steril. 26, 167-174.

Pommer, A.C., Linfor, J.J., Meyers, S.A., 2002. Capacitation and acrosomal exocytosis are enhanced by incubation of stallion spermatozoa in a commercial semen extender. Theriogenology 57, 1493-1501.

Salazar-Valencia, F., 1983. Embryo recovery rates in mares of the Pasofino Colombiano breed and deep freezing stallion semen in the tropics. Theriogenology 19, 146 (abstract).

Samper, J.C., 1995. Stallion semen cryopreservation: Male affecting pregnancy rates. Proceedings Society Study of Theriogenology, p. 160.

Samper, J.C., Hellander, J.C., Crabo, B.G., 1991. Relationship between fertility of fresh and frozen stallion semen and semen quality. J. Reprod. Fertil., Suppl. 44, 107-114.

Schembri, M.A., Major, D.A., Suttie, J.J., Maxwell, W.M., Evans G., 2002. Capacitation-like changes in equine spermatozoa throughout the cryopreservation process. Reprod. Fertil. Dev. 14, 225-233.

Sieme, H., Bonk, A., Hamann, H., Klug, E., Katila, T., 2004. Effects of different artificial insemination techniques and sperm doses on fertility of normal mares and mares with abnormal reproductive history. Theriogenology 62, 915-928.

Sieme, H., Schafer, T., Stout, T.A., Klug, E., Waberski, D., 2003. The effects of different insemination regimes on fertility in mares. Theriogenology 60, 1153-1164. 
SIRE,.1985, 1986 ... 2004. Analyse des résultats de la monte et analyse des naissances (Analysis of results of breeding season and analysis of births), Institut du Cheval and Haras Nationaux (Eds). One booklet /year.

Squires, E.L., Barbacini, S., Necchi, D., Reger, H.P., Bruemmer, J.E., 2003. Simplified strategy for insemination of mares with frozen semen. Proceedings 49th AAEP, New Orleans, USA. Internet Publisher: International Veterinary Information Service, Ithaca NY http://www.ivis.org/proceedings/AAEP/2003/squires/chapter_frm.asp?LA=1

Squires, E.L., Keith, S.L., Graham, J.K., 2004. Evaluation of alternative cryoprotectants for preserving stallion spermatozoa. Theriogenology 62, 1056-1065.

Tischner, M., 1979. Evaluation of deep-frozen semen in stallions. J. Reprod. Fertil., Suppl. 27, 53-59.

Vidament, M., Daire, C., Yvon, J.M., Doligez, P., Bruneau, B., Magistrini, M., Ecot, P., 2002. Motility and fertility of stallion semen frozen with glycerol and/or dimethyl formamide. In: Evans, M.J. (Ed.), Special Issue, Equine Reproduction VIII, Theriogenology 58, 249-251.

Vidament, M., Dupéré, A.M., Julienne, P., Evain, A., Noue, P., Palmer, E., 1997. Equine frozen semen: freezability and fertility field results. Theriogenology 48, 907-917.

Vidament, M., Ecot, P., Noue, P., Bourgeois, C., Magistrini, M., Palmer, E., 2000a. Centrifugation and addition of glycerol at $22^{\circ} \mathrm{C}$ instead of $4{ }^{\circ} \mathrm{C}$ improve post-thaw motility and fertility of stallion spermatozoa. Theriogenology 54, 907-919.

Vidament, M., Magistrini, M., Palmer, E., Clément, F., 2000b. Equine artificial insemination in French National Studs. Reprod. Dom. Anim., Suppl. 6, 61-66.

Vidament, M., Vincent, P., Yvon, J.M., Bruneau, B., Martin, FX., 2005. Glycerol in semen extender is a limiting factor in the fertility in asine and equine species. Proceedings 4 th International Symposium on Stallion Reproduction, October 21-23, Hannover, Germany, abstract accepted.

Vidament, M., Yvon, J.M., Couty, I., Arnaud, G., Nguekam-Feugang, J., Noue, P., Cottron, S., Le Tellier, A., Noel, F., Palmer, E., Magistrini, M., 2001. Advances in cryopreservation of stallion semen in modified INRA82. Anim. Reprod. Sci. 68, 201-218.

Volkmann, D.H., van Zyl, D., 1987. Fertility of stallion semen frozen in 0.5-ml straws. J. Reprod. Fertil., Suppl. 35, 143-148.

Wilhelm, K.M., Graham, J.K., Squires, E.L., 1996. Comparison of the fertility of cryopreserved stallion spermatozoa with sperm motion analyses, flow cytometric evaluation, and zona-free hamster oocyte penetration. Theriogenology 46, 559-578.

Woods, J., Bergfeldt, D.R., Ginther, O.J., 1990. Effects of time of insemination relative to ovulation on pregnancy rate and embryonic-loss rate in mares. Equine Vet. J. 22, 410-415. 
Table 1

Equine frozen semen: evolution of freezing protocols and frozen semen production in the French National Stud (1985-2005).

\begin{tabular}{|c|c|c|c|c|c|c|c|}
\hline Year & $\begin{array}{c}\text { Basic } \\
\text { protocol }^{\text {a }}\end{array}$ & $\begin{array}{l}\text { in compari- } \\
\text { son with }\end{array}$ & $\begin{array}{l}\text { Correction } \\
\text { for sperm } \\
\text { loss }\end{array}$ & $\begin{array}{l}\text { No of } \\
\text { freezing } \\
\text { centres }\end{array}$ & $\begin{array}{l}\text { No of } \\
\text { stallions }\end{array}$ & $\begin{array}{c}\text { No of frozen } \\
\text { ejaculates }\end{array}$ & $\begin{array}{c}\text { Rate of selected } \\
\text { ejaculates (\%) }\end{array}$ \\
\hline 1985 & 37E1/4E2 & & no & 1 & 6 & 93 & 58 \\
\hline 1986 & 37E1/4E2 & & no & 1 & 10 & 109 & 52 \\
\hline 1987 & 37E1/4E2 & & no & 1 & 10 & 156 & 40 \\
\hline 1988 & 37E1/4E2 & & no & 1 & 10 & 223 & 48 \\
\hline 1989 & 37E1/4E2 & & no & 2 & 15 & 224 & 56 \\
\hline 1990 & 37E1/4E2 & & no & 2 & 41 & 363 & 35 \\
\hline 1991 & 37E1/4E2 & & no & 4 & 42 & 608 & 32 \\
\hline 1992 & 37E1/4E2 & & no & 4 & 47 & 635 & 46 \\
\hline 1993 & 37E1/4E2 & & no & 4 & 65 & 772 & 26 \\
\hline 1994 & 37E1/4E2 & & no & 4 & 58 & 696 & 44 \\
\hline 1995 & 37E1/4E2 & 37E1/22E2 & yes & 4 & 64 & 521 & 46 \\
\hline 1996 & 37E1/4E2 & 37E1/22E2 & yes & 4 & 70 & 703 & 67 \\
\hline 1997 & 37E1/22E2 & $22 \mathrm{E} 2 / 22 \mathrm{E} 2$ & yes & 4 & 87 & 988 & 61 \\
\hline 1998 & $37 \mathrm{E} 1 / 22 \mathrm{E} 2$ & 22E2/22E2 & yes & 4 & 84 & 974 & 79 \\
\hline 1999 & 37E1/22E2 & 37E1/22E2Glu & yes & 5 & 124 & 1622 & 83 \\
\hline 2000 & 37E1/22E2 & 37E1/22E2Glu & yes & 5 & 141 & 2051 & 78 \\
\hline 2001 & $37 \mathrm{E} 1 / 22 \mathrm{E} 2$ & 37Milk/22E2 & yes & 5 & 123 & 1821 & 83 \\
\hline 2002 & 37E1/22E2 & 37Milk/22E2 & yes & 5 & 127 & 1810 & 87 \\
\hline 2003 & 37Milk/22E2 & & yes & 5 & 133 & 1931 & 86 \\
\hline 2004 & 37Milk/22E2 & & yes & 5 & 117 & 1873 & 88 \\
\hline 2005 & 37Milk/22E2 & & yes & 4 & 114 & 1802 & 81 \\
\hline
\end{tabular}

${ }^{\text {a }}$ Combination of temperatures and extenders before freezing: the temperature $\left({ }^{\circ} \mathrm{C}\right)$ and extender of the first dilution / the temperature $\left({ }^{\circ} \mathrm{C}\right)$ and extender of the second dilution after the centrifugation; example : 37E1/4E2 : first dilution at $37^{\circ} \mathrm{C}$ in E1, cooling to $4^{\circ} \mathrm{C}$ and second dilution after centrifugation at $4^{\circ} \mathrm{C}$ in E2.; E1 : INRA82 + egg yolk (2\%, v/v); E2 : E1 + glycerol (2.5\%, v/v); Glu : 50 mM glutamine; Milk: UHT (Ultra Heat Temperature) skim milk. 
Table 2

Equine frozen semen: evolution of insemination strategies, number of inseminated mares and fertility (per-cycle pregnancy rate and foaling rate) in the French National Stud (1985-2004) ${ }^{\mathrm{a}}$.

\begin{tabular}{|c|c|c|c|c|c|c|c|c|c|}
\hline \multirow{3}{*}{ Year } & \multicolumn{7}{|c|}{ Frozen semen } & \multirow{3}{*}{$\begin{array}{l}\begin{array}{l}\text { Hand } \\
\text { mating }\end{array} \\
\text { Foa- } \\
\text { ling } \\
\text { rate } \\
(\%) \\
\end{array}$} & \multirow{3}{*}{$\begin{array}{l}\begin{array}{l}\text { Fresh } \\
\text { semen }\end{array} \\
\text { Foa- } \\
\text { ling } \\
\text { rate } \\
(\%)\end{array}$} \\
\hline & \multicolumn{3}{|c|}{ Insemination recommendations } & \multirow[b]{2}{*}{$\begin{array}{l}\text { Number } \\
\text { AI } \\
\text { centres }{ }^{\mathrm{d}}\end{array}$} & \multirow{2}{*}{$\begin{array}{l}\text { Number } \\
\text { insemi- } \\
\text { nated } \\
\text { mares }\end{array}$} & \multirow{2}{*}{$\begin{array}{l}\text { Per-cycle } \\
\text { pregnancy } \\
\text { rate }(\%)\end{array}$} & \multirow{2}{*}{$\begin{array}{l}\text { Foa- } \\
\text { ling } \\
\text { rate } \\
(\%)\end{array}$} & & \\
\hline & $\begin{array}{l}\text { Basic } \\
\text { protocol }^{\text {bc }}\end{array}$ & $\begin{array}{l}\text { in comparison } \\
\text { with bc }\end{array}$ & $\begin{array}{l}\text { Num- } \\
\text { ber AI/ } \\
\text { cycle }\end{array}$ & & & & & & \\
\hline 1985 & $300 \times 48 h$ & & 1 & 6 & 93 & 29 &.$^{\mathrm{e}}$ & . &. \\
\hline 1986 & $300 \times 48 h$ & & 1 & 6 & 125 & 37 & . & . & . \\
\hline 1987 & $300 \times 48 h$ & & 1 & 10 & 200 & 36 & 60 & 60 & 61 \\
\hline 1988 & $300 \times 48 h$ & $150 \times 24 \mathrm{~h}$ & 1 & 10 & 311 & 32 & 62 & 62 & 66 \\
\hline 1989 & $300 \times 48 h$ & $150 \times 24 h$ & 2 & 12 & 327 & 30 & 56 & 62 & 66 \\
\hline 1990 & $300 \times 48 h$ & $150 \times 24 h$ & 2 & 16 & 248 & 28 & 45 & 56 & . \\
\hline 1991 & $300 \times 48 h$ & $300 \& 150 \times 24 h$ & 2 & 29 & 273 & 31 & 48 & 57 & 63 \\
\hline 1992 & $300 \times 48 h$ & $300 \& 150 \times 24 h$ & 2 & 37 & 499 & 27 & 49 & 61 & 63 \\
\hline 1993 & $300 \times 48 h$ & $300 \& 150 \times 24 h$ & 2 & 40 & 372 & 29 & 48 & 62 & 62 \\
\hline 1994 & $300 \times 48 h$ & $300 \& 150 \times 24 h$ & 2 & 40 & 292 & 34 & 52 & 60 & 64 \\
\hline 1995 & $400 \times 48 h$ & $400 \& 200 \times 24 h$ & 2 & 41 & 307 & 43 &. &. &. \\
\hline 1996 & $400 \times 24 h$ & & 2 & 44 & 408 & 44 & 61 & . & . \\
\hline 1997 & $400 \times 24 h$ & & 2 & 48 & 481 & 53 & 72 & 63 & 63 \\
\hline 1998 & $400 \times 24 h$ & & 2 & 54 & 704 & 49 & 69 & 64 & 66 \\
\hline 1999 & $400 \times 24 h$ & & 2 & 66 & 1032 & 47 & . &. & . \\
\hline 2000 & $400 \times 24 h$ & & 2 & 74 & 1326 & 49 & 66 & 63 & 63 \\
\hline 2001 & $400 \times 24 h$ & & 2 & $92+24$ & 1390 & 49 & 66 & 63 & 68 \\
\hline 2002 & $400 \times 24 h$ & & 2 & $93+32$ & 1503 & 48 & 64 & 64 & 69 \\
\hline 2003 & $400 \times 24 h$ & & 2 & $95+46$ & 1723 & 45 & 64 & 64 & 65 \\
\hline 2004 & $400 \times 24 h$ & & 2 & $97+65$ & 1990 & 46 & & & \\
\hline
\end{tabular}

a This table is not directly linked to the table 1 because at least half of the used semen in one year was frozen in the previous winter, the rest was stored for 1 or more years, so modification of the freezing protocol and correction of sperm loss could have a moderate effect the first year on the fertility.

${ }^{\mathrm{b}}$ Total number of spermatozoa $\left(\mathrm{x} 10^{6}\right)$ per AI x interval between AI. Example: 300 \& $150 \mathrm{x} 24 \mathrm{~h}$ : first AI with $300 \times 10^{6}$ total sperm, then $150 \times 10^{6} 24$ h later and every $24 \mathrm{~h}$ until ovulation.

${ }^{\mathrm{c}}$ It is not known to which extent the recommendations were followed by veterinarians and technicians.

${ }^{\mathrm{d}}$ Number of National Stud insemination centres+ number of private insemination centres

${ }^{\mathrm{e}}$ Missing data 
Table 3

Post-thaw motion characteristics of spermatozoa frozen after 3 protocols of the first dilution (Experiment 2) .

\begin{tabular}{cccccc}
\hline $\begin{array}{c}\text { First extender } \\
\text { Freezing extender }\end{array}$ & $\begin{array}{c}\text { E1 } \\
\text { E2 }^{\text {bc }}\end{array}$ & $\begin{array}{c}\text { E1S } \\
\text { E2S }^{\text {bd }}\end{array}$ & $\begin{array}{c}\text { INRA82 } \\
\text { E2 }^{\mathrm{c}}\end{array}$ & $\begin{array}{c}\text { Milk }^{\mathrm{e}} \\
\text { E2 }^{\mathrm{c}}\end{array}$ & $\begin{array}{c}\text { Pooled } \\
\text { S.E.M. }\end{array}$ \\
\hline Motility (\%) & 46 & 45 & 48 & 48 & 2 \\
VAP $(\mu \mathrm{m} / \mathrm{sec})^{\mathrm{f}}$ & 76 & 78 & 77 & 79 & 0.9 \\
${\text { Viability CFDA/IP }(\%)^{\mathrm{g}}}^{\mathrm{g}}$ & 56 & 58 & 54 & 59 & 15 \\
\hline
\end{tabular}

${ }^{a}$ Freezing protocol: first dilution at $37^{\circ} \mathrm{C}$ in various centrifugation extenders, cooling to $22^{\circ} \mathrm{C}$ and second dilution after centrifugation in freezing extender at $22^{\circ} \mathrm{C}$ before moderate cooling to $4^{\circ} \mathrm{C}$ and freezing. Values are means of 10 split ejaculates (5 stallions $\mathrm{x} 2$ ejaculates)

${ }^{\mathrm{b}} \mathrm{E} 1$ : INRA82 + egg yolk, 2\%, v/v; E2 : E1 + glycerol, 2.5\%, v/v.

${ }^{c}$ E1 and E2 made like usually with liquid UHT (Ultra Heat Temperature) skim milk.

${ }^{\mathrm{d}}$ E1S et E2S: E1 and E2 made with non fat dry milk (Sanalac TM).

${ }^{\mathrm{e}}$ Milk: UHT (Ultra Heat Temperature) skim milk.

${ }^{\mathrm{f}}$ VAP: average path velocity.

${ }^{\mathrm{g}}$ Viability was determined with flow cytometry after staining with carboxyfluorescein diacetate (CFDA) and propidium iodide (PI).

Table 4

Post-thaw motion characteristics and fertility of spermatozoa frozen after 2 protocols of the first dilution (in either E1 or in milk) (Experiment 3) a.

\begin{tabular}{|c|c|c|c|}
\hline $\mathrm{E}^{\mathrm{b}}$ & Milk ${ }^{\mathrm{c}}$ & & Pooled \\
\hline $\begin{array}{l}\text { No. of No. of Means } \\
\text { ejaculates cycles }\end{array}$ & $\begin{array}{cc}\begin{array}{c}\text { No. of } \\
\text { ejaculates }\end{array} & \begin{array}{c}\text { No. of } \\
\text { cycles }\end{array} \\
\end{array}$ & Means & SEM \\
\hline
\end{tabular}

Winter 2001: 21 stallions

Motility (\%)

$\operatorname{VAP}(\mu \mathrm{m} / \mathrm{sec})$

Winter 2002: 104 stallions

Motility (\%)

$\operatorname{VAP}(\mu \mathrm{m} / \mathrm{sec})$

No. straws / ejaculate
102

867
54

93

52

84

91 a
127

922

(1)

(1)

Breeding seasons 2001 \& 2002:

(23 stallions $\mathrm{x}$ breeding seasons)

Per-cycle pregnancy rate (\%)

$353 \quad 49$

$335 \quad 48$

${ }^{a}$ Different letters within a row denote differences $(\mathrm{P}<0.05)$. Either E1 or milk was used as centrifugation extenders. Freezing protocol was first dilution at $37^{\circ} \mathrm{C}$ in centrifugation extender, cooling to $22^{\circ} \mathrm{C}$ and second dilution after centrifugation in freezing extender E2 at $22^{\circ} \mathrm{C}$ before moderate cooling to $4^{\circ} \mathrm{C}$ and freezing.

${ }^{\mathrm{b}}$ E1: INRA82 + egg yolk, 2\%, v/v; E2 : E1 + glycerol, 2.5\%, v/v.

${ }^{c}$ Milk: UHT (Ultra Heat Temperature) skim milk.

${ }^{\mathrm{d}}$ VAP: average path velocity. 
Table 5

Per-cycle pregnancy rates with frozen semen after two protocols of insemination ${ }^{\mathrm{a}}$.

\begin{tabular}{lll}
\hline & \multicolumn{2}{c}{ Protocol of insemination } \\
Number of total spermatozoa $\left(10^{6}\right)$ & 300 & 300 \\
First AI & 150 & 300 \\
Subsequent AIs & $24 \mathrm{~h}$ & $24 \mathrm{~h}$ \\
Interval between AIs until ovulation & $33 \quad(\mathrm{n}=40)$ & $47 \quad(\mathrm{n}=36)$ \\
\hline Per-cycle pregnancy rate (\%) & $33(\mathrm{n}=131)$ & $45 \quad(\mathrm{n}=129)$ \\
Breeding season 1994 & $33 \mathrm{~b}(\mathrm{n}=171)$ & $45 \mathrm{a}(\mathrm{n}=165)$ \\
Breeding season 1995 &
\end{tabular}

${ }^{a}$ Different letters within a row denote differences $(\mathrm{P}<0.05)$. Freezing protocol was 37E1/4E2: first dilution at $37^{\circ} \mathrm{C}$ in E1, moderate cooling to $4^{\circ} \mathrm{C}$ and second dilution after centrifugation in freezing extender E2 at $4^{\circ} \mathrm{C}$ before freezing. E1 : INRA82 + egg yolk, 2\%, v/v; E2 : E1 + glycerol, $2.5 \%, \mathrm{v} / \mathrm{v}$.

Table 6

Present French system: freezing protocol 37Milk/22E2 and insemination strategy.

\begin{tabular}{|c|c|c|}
\hline $\begin{array}{l}\text { Semen } \\
\text { collection }\end{array}$ & $\begin{array}{l}\text { Frequency } \\
\text { Months }\end{array}$ & $\begin{array}{l}3 \text { times / week } \\
\text { October to February }\end{array}$ \\
\hline $\begin{array}{l}\text { Centri- } \\
\text { fugation }\end{array}$ & $\begin{array}{l}\text { Centrifugation extender } \\
\text { Sperm numbers } \\
\text { Total volume (semen + milk) } \\
\text { Cooling until centrifugation } \\
\text { Centrifugation } \\
\text { Pellet volume }\end{array}$ & $\begin{array}{l}\text { UHT (Ultra Heat Temperature) skim milk at } 37^{\circ} \mathrm{C} \\
\text { in general } 2.5 \times 10^{9} \text { spermatozoa / } 50 \text { ml-tube } \\
45 \mathrm{ml} \text { (maximum } 15 \mathrm{ml} \text { semen) } \\
\text { in water-bath at } 22^{\circ} \mathrm{C} \text { for } 10 \mathrm{~min} \\
600 \mathrm{~g} \mathrm{x} 10 \text { min at ambient temperature } \\
3.5 \mathrm{ml} \text { (until corner of the conical tube) }\end{array}$ \\
\hline $\begin{array}{l}\text { Addition } \\
\text { of freezing } \\
\text { extender }\end{array}$ & $\begin{array}{l}\text { Freezing extender } \\
\text { 1st addition of extender at } 22^{\circ} \mathrm{C} \\
\text { Estimation of spz concentration } \\
\text { 2nd addition of extender at } 22^{\circ} \mathrm{C} \\
\text { Final glycerol concentration } \\
\text { Final seminal plasma concentration } \\
\end{array}$ & $\begin{array}{l}\text { INRA82 + egg yolk }(2 \%, \mathrm{v} / \mathrm{v})+\text { glycerol }(2.5 \%, \mathrm{v} / \mathrm{v}) \\
\text { about half of the calculated volume } \\
\text { with haemocytometer } \\
\text { adjustment to } 100 \times 10^{6} \text { spermatozoa } / \mathrm{ml} \\
1.2 \text { to } 2.3 \text { (mean } 2.1 \% \text { ) } \\
1 \text { to } 15 \text { (mean } 4.4 \% \text { ) }\end{array}$ \\
\hline $\begin{array}{l}\text { Cooling and } \\
\text { freezing }\end{array}$ & $\begin{array}{l}\text { Cooling to } 4^{\circ} \mathrm{C} \\
\text { Straws volume } \\
\text { Stay at } 4^{\circ} \mathrm{C} \\
\text { Freezing }\end{array}$ & $\begin{array}{l}\text { in } 50 \text {-ml tubes (containing variable volume) for } 1 \mathrm{~h} 15 \mathrm{~min} \\
0.5 \mathrm{ml} \text {, loaded at } 4^{\circ} \mathrm{C} \\
3 \text { to } 4 \text { ejaculates are frozen together in the same machine, so } \\
\text { sperm could wait at } 4^{\circ} \mathrm{C} 0 \text { to } 60 \mathrm{~min} \\
-40^{\circ} \mathrm{C} / \mathrm{min} \text { to }-60^{\circ} \mathrm{C} / \mathrm{min} \text {, until }-140^{\circ} \mathrm{C} \text {, then in liquid } \mathrm{N} 2\end{array}$ \\
\hline $\begin{array}{l}\text { Selection of } \\
\text { ejaculates }\end{array}$ & Selection of ejaculates & $\begin{array}{l}\text { if rapid motility } \geq 35 \% \\
\text { on } \geq 2 \text { separated straws diluted in INRA82 (1v/5v) }\end{array}$ \\
\hline $\begin{array}{l}\text { Straws and } \\
\text { Mare } \\
\text { management }\end{array}$ & $\begin{array}{l}\text { No. of straws per mare per season } \\
\text { Frequency of scanning mares } \\
\text { Thawing } \\
\text { Site of insemination } \\
\text { Number of total spz / AI } \\
\text { Number of AI / cycle } \\
\text { AI frequency }\end{array}$ & $\begin{array}{l}48 \text { straws ( } 2400 \times 10^{6} \text { total sperm) } \\
\text { every day when follicle } \geq 30 \mathrm{~mm} \\
30 \text { sec in water bath at } 37^{\circ} \mathrm{C} \text {, no further preparation of semen } \\
\text { into the uterine body } \\
400 \times 10^{6} \text { ( } 8 \text { straws) } \\
2 \\
\text { every day until ovulation, no AI post-ovulation }\end{array}$ \\
\hline
\end{tabular}


Table 7

Production of frozen semen in the French National Stud (2003-2005) ${ }^{\mathrm{a}}$.

\begin{tabular}{lccc}
\hline & 2003 & 2004 & 2005 \\
\hline Number of stallions & 133 & 117 & 114 \\
Frozen ejaculates: & 1931 & 1873 & 1802 \\
$\quad$ Rapid motility (\%) & 51 & 51 & 49 \\
$\quad$ Progressive motility (\%) & 39 & 40 & 37 \\
Selected ejaculates after thawing : & & & \\
$\quad$ Rapid motility (\%) & 55 & 55 & 55 \\
$\quad$ Progressive motility (\%) & 42 & 42 & 42 \\
$\quad$ Rate of selected ejaculates (\%) & 86 & 88 & 81 \\
$\quad$ Number of straws / frozen ejaculates & 84 & 86 & 78 \\
Number of mares per season (48 straws) & 2857 & $/$ & 2375 \\
Ratio: & & & \\
$\quad$ mares per season / frozen ejaculates & 1.5 & $/$ & 1.4 \\
Stallions with unfreezable semen ${ }^{\mathrm{b}}$ (\%) & $9 \%$ & $6 \%$ & $15 \%$ \\
\hline
\end{tabular}

${ }^{a}$ Freezing protocol: $37 \mathrm{Milk} / 22 \mathrm{E} 2$, first dilution at $37^{\circ} \mathrm{C}$ in milk (UHT (Ultra Heat Temperature) skim milk), cooling to $22^{\circ} \mathrm{C}$ and second dilution after centrifugation in freezing extender E2 at $22^{\circ} \mathrm{C}$ before moderate cooling to $4^{\circ} \mathrm{C}$ and freezing. E2: INRA82 + egg yolk $(2 \%, \mathrm{v} / \mathrm{v})+$ glycerol $(2.5 \%, \mathrm{v} / \mathrm{v})$.

b Stallions with less than 33\% post-thawing selected ejaculates. 
Table 8

Proposition of codes associated with frozen semen offer for a mare per season.

Codes for minimal number of spermatozoa for the breeding season

$$
\begin{aligned}
& \text { A*** } \quad \geq 3 \times 750.10^{6} \text { total sperm i.e. } \geq 2.25 \times 10^{9} \text { total sperm in } \geq 6 \text { straws } \\
& \text { (for } 3 \text { cycles) } \\
& \text { A** } \quad \geq 2 \times 750.10^{6} \text { total sperm i.e. } \geq 1.5 \times 10^{9} \text { total sperm in } \geq 4 \text { straws } \\
& \text { (for } 2 \text { cycles) } \\
& \text { A* } \quad \geq 1 \times 750.10^{6} \text { total sperm in } \geq 2 \text { straws } \\
& \text { (for } 1 \text { cycle) }
\end{aligned}
$$

Codes for minimal post-thawing motility (total or rapid)
A $\quad \geq 35 \%$
B $\quad<35 \%$ or unspecified

Codes for maximal final glycerol concentration

A

$<4 \%(\mathrm{v} / \mathrm{v})$

B

$\geq 4 \%(\mathrm{v} / \mathrm{v})$ or unspecified

Frozen semen offer is coded with 3 letters, based on total sperm number available per mare and per season (first letter), on post-thaw total or rapid motility (second letter) and on final glycerol concentration (third letter). For instance, a frozen semen offer A***AA is very good technically (in quantity (sufficient number for 3 cycles) and in quality), an offer BAA indicates that sperm is very good in quality but that the number of spermatozoa are lower than the minimum number of spermatozoa required for one cycle and an offer $A^{* * *} A B$ indicates that enough spermatozoa are provided for 3 cycles, with good motility but with unspecified or too high glycerol concentration. 


\section{Table 9}

Information form on frozen semen.

Name and address of the collection and the freezing centre:

Name and identification (registration no.) of the stallion:

Date of collection (and number if more than one collect/day):

Identification of the straws:

Volume per straw (ml):

Concentration of sperm (millions of spermatozoa $\left(10^{6}\right)$ per ml):

Total number of sperm per straw (millions of spermatozoa $\left(10^{6}\right)$ :

Motility of the ejaculate after freezing and thawing:

Total number of motile sperm ( $\geq 35 \%$ ) per straw:

Final concentration of glycerol in the straw:

Thawing protocol for the straws:

Location of frozen semen within the container: 


\section{Figure 1}
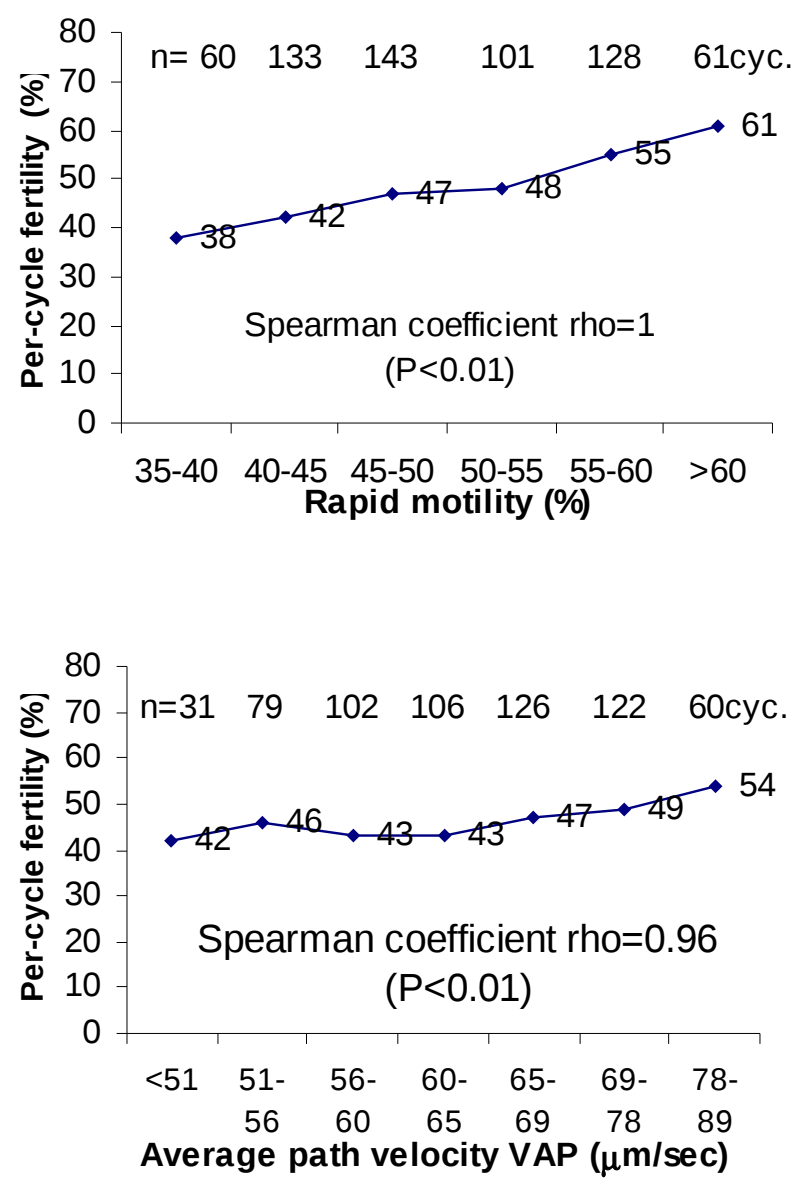

Figure 1

Per-cycle pregnancy rates with equine frozen semen categorized by motion characteristics of spermatozoa after thawing (rapid motility and average path velocity (VAP)).

${ }^{a}$ Each cycle of breeding season 1999, positive or negative after a pregnancy diagnosis, was associated with the values of 2 criteria measured on the corresponding ejaculate during the control analysis made at selection. Then, for each criteria, lines of the file were ranked by increasing value of this criterion and assembled in classes with more or less the same number of cycles. Then fertility was calculated by class (positive cycles / total cycles of the class) and correlation between class value and fertility was calculated using the non parametric coefficient of Spearman between center of the class and fertility. The number of cycles within each class is indicated above each point (n, cyc.). 


\section{Figure 2}

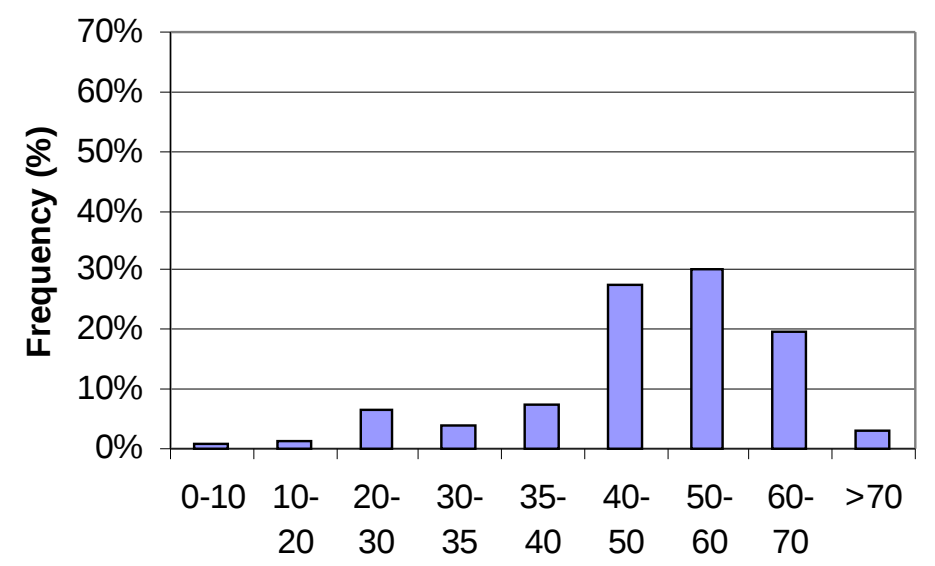

Rapid motility (mean per stallion) (\%)

Figure 2

Distribution of the mean post-thaw rapid motility per year of 344 stallions (2003 to 2005)

Freezing protocol 37Milk/22E2: first dilution at $37^{\circ} \mathrm{C}$ in UHT (Ultra Heat Treatment) skim milk, cooling to $22^{\circ} \mathrm{C}$ and second dilution after centrifugation in freezing extender E2 at $22^{\circ} \mathrm{C}$ before moderate cooling to $4^{\circ} \mathrm{C}$ and freezing. E2: INRA82 + egg yolk (2\%, v/v) + glycerol $(2.5 \%, v / v)$.

Figure 3

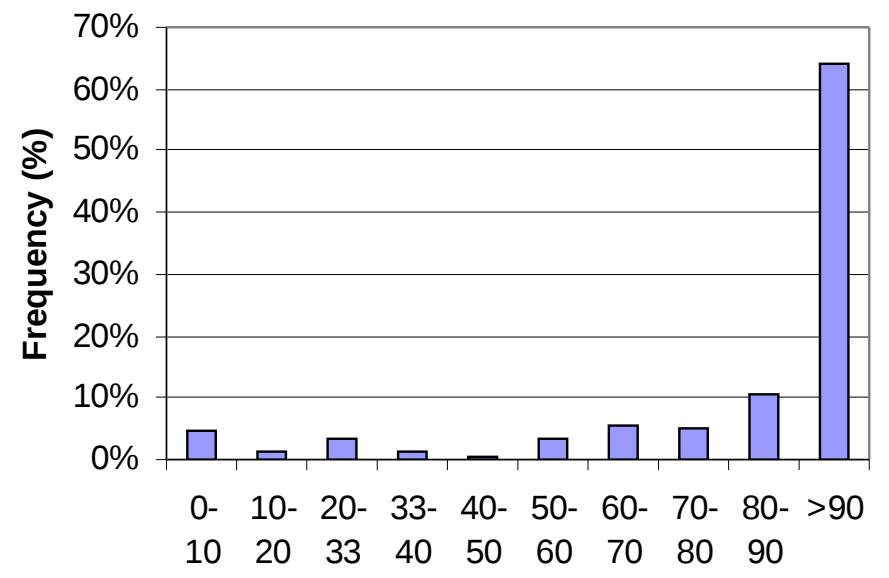

Semen freezability of stallion (\%)

Figure 3

Distribution of semen freezability of 344 stallions (number of selected ejaculates / number of frozen ejaculates for a given stallion per year) (2003 to 2005).

Freezing protocol 37Milk/22E2: first dilution at $37^{\circ} \mathrm{C}$ in UHT (Ultra Heat Treatment) skim milk, cooling to $22^{\circ} \mathrm{C}$ and second dilution after centrifugation in freezing extender E2 at $22^{\circ} \mathrm{C}$ before moderate cooling to $4^{\circ} \mathrm{C}$ and freezing. E2: INRA82 + egg yolk $(2 \%, v / v)+$ glycerol $(2.5 \%, v / v)$. 